\title{
MRS Prepares for the Future
}

2008 is a landmark year for the Materials Research Society. It marks the 35 th anniversary of the Society and the retirement of John B. Ballance after 25 years of distinguished service as the MRS Executive Director. These events offer us the opportunity to pause, reflecting both on the past and projecting into the future.

John B. Ballance has been a remarkable steward of MRS, catalyzing its transformation from a society with one technical meeting serving a couple of hundred U.S.-based scientists to today's vibrant Society with international conferences, workshops, and exhibits serving a diverse international scientific community. John has grown and maintained a truly professional headquarters staff, seeing it blossom from two to 38 employees, many with 10-25 years of service to the Society. In short, John loves MRS. His passion and service to the Society is largely responsible for the MRS we know today.

In the 35 years since our founding, MRS has grown from a few hundred members to a 15,000-member society. Technical excellence and interdisciplinary programming have made MRS the home for materials research. Our meetings cover the broad spectrum of cutting-edge materials science while the MRS Bulletin and the Journal of Materials Research are highly respected archives of progress in materials research. In addition, MRS is a leader in public outreach, providing an effective voice for the broad materials community.

As Jonas Salk once said, "The reward for work well done is the opportunity to do more." MRS will do just that.

Here are a few ways that we see MRS making significant impacts in the future:

MRS will continue to promote technical excellence. This is our foundation. We will continue to encourage high-quality research and provide a unified forum for materials advancements in physical and biological sciences.

MRS will continue to advance interdisciplinary materials research to improve the quality of life. We believe that MRS can be a catalyst for multidisciplinary responses to global climate change, water resource scarcity, and other environmental concerns. Our approach will be broad and comprehensive, reflecting MRS as a whole.
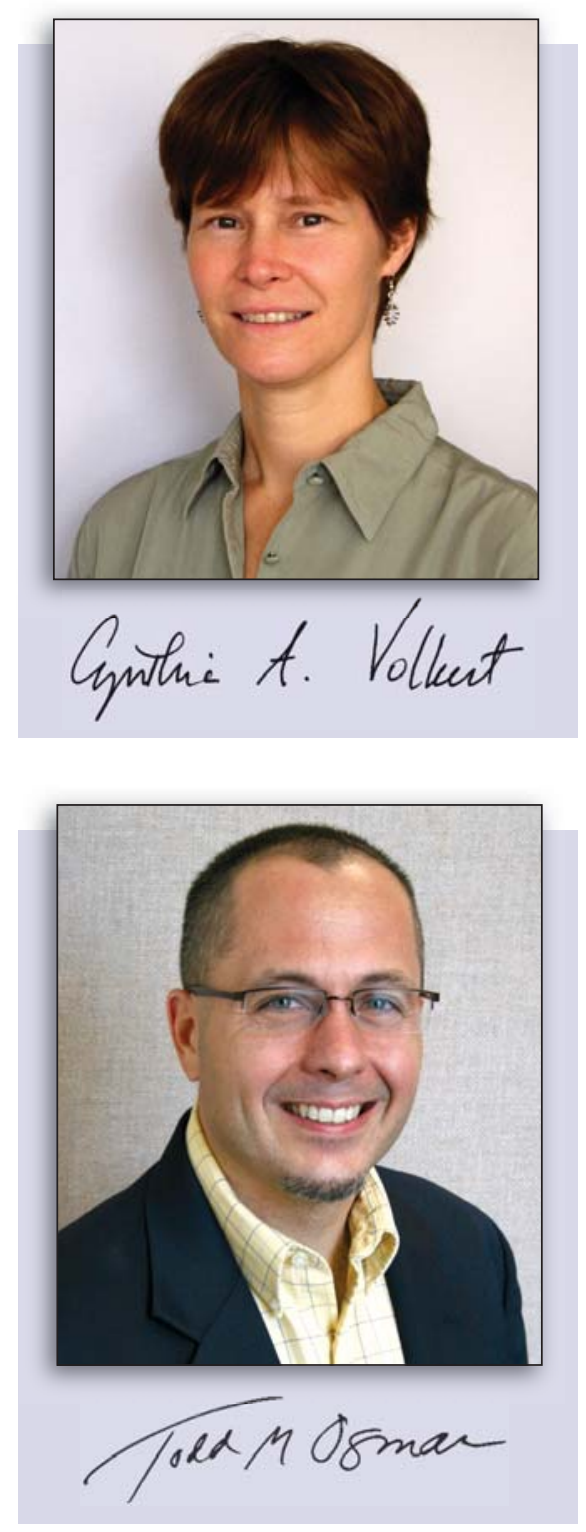

Chemists, biologists, physicists, materials scientists, and engineers will all participate. All materials classes, ranging from metals to polymers, ceramics to metallic glasses, and nanomaterials to metamaterials, will contribute. MRS Meetings, the MRS Bulletin, the Journal of Materials Research, and the Materials Gateway will both promote and reflect the interdisciplinary approach that will produce scientific solutions to society's challenges.

But technical progress, while necessary, will not be sufficient to produce the needed changes. We must continue MRS public outreach efforts. We must also promote collaboration between the scientific community and non-scientists in advocating for socially viable solutions.

The global materials enterprise must be engaged in this process. As such, we will continue to promote materials research throughout the world. MRS will be seen as a strong partner for multilateral projects, mutually benefiting the materials community, partner organizations, and MRS.

We will meet the Gathering Storm challenge, doing our part to produce the next generation of materials researchers. Strange Matter and other STEM (scientific, technical, engineering, and mathematics) education efforts will help to "feed the scientific community's pipeline." Crosscutting, multidisciplinary engagement of university faculty and students will allow the MRS baton to be carried into the future.

And we will continue to lead diversity efforts. The Women in Materials Science and Engineering Breakfast series and the Women's Leadership Series (being launched at the 2008 MRS Fall Meeting) will provide effective forums for dialogue and advancement. We will also engage the larger scientific community to produce broad-reaching change.

In closing, we return again to the words of Jonas Salk: "There is hope in dreams, imagination, and in the courage of those who wish to make those dreams a reality." We dream of a world with a stable environment and readily available sources of energy and water. We imagine a vibrant, interdisciplinary materials enterprise that engages all demographics and geographic regions. And it is our firm belief that MRS will continue to be a leader in these endeavors, serving the scientific community and advancing the global quality of life.

CYNTHIA A. VOLKERT 2008 MRS President

TODD M. OSMAN MRS Executive Director

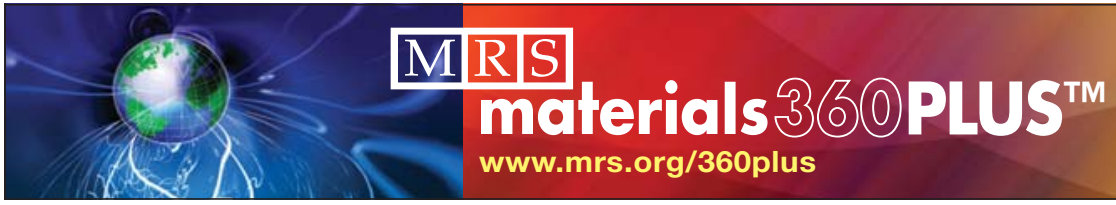

